\title{
CLASSIFICATIONS OF ENVIRONMENTAL QUALITY EFFECTS: THE CASE OF CANADIAN CITIES
}

\section{Dimitrios Giannias, Eleni Sfakianaki}

\section{Introduction}

Environmental amenities have been associated with economic development since earliest time; for example, Egypt and Mesopotamia developed in the river valleys of the Nile, Tigris and Euphrates in the ancient times, mainly because the environment in these valleys was favorable for agriculture. Although man-made facilities are often needed to complement a natural environment, resorts such as Greek Islands and Florida beaches are, in effect, selling a type of environment peculiar to the locality in which they are situated. According to Mulligan et al. [24], amenities are site- or region-specific goods and services that make some locations particularly attractive for living and working and Smith [30] argues that amenities influence quality of life or social wellbeing and in this respect a bundle of amenities can influence decisions on the purchase of households, production of firms and other locational dilemmas.

In recent years increasing concern has focused on the consequences and prospects of continuing economic growth. Increases in gross national product lead inevitably to increased pollution, congestion and other external diseconomies that affect negatively and tend to decrease the apparent increase in economic welfare [23]. Nordhaus and Tobin [25], Easterlin [8] and King [20] attempted to provide measures of this reduction at the macroeconomic level. At the microeconomic level, Walters [32] has attempted to supply improved measures of these diseconomies, and Griffin [15] and Baumol and Oates [1] have attempted to devise relevant methods of control and to estimate their costs. Forrester [10] and
Meadows et al. [22] argued that the finiteness of world resources limits the growth of gross world product and suggest policies aimed at achieving zero growth rate. Beckerman [2] defended economic growth based on facts of economic life. A few years before them, Galbraith [11] took the position that once the basic needs of the population have been met, further increases in the gross national product through the production of goods which consumers and governments have been made to want, may not increase welfare in any meaningful sense: such production preempts public expenditure in amenities which would in fact be «preferred» by the population.

Each of these arguments converges on the conclusion that less importance should be attached to the production and consumption of goods and more to the other aspects of human experience that are usually taken into consideration by what is broadly understood as environmental quality or quality of life. This perspective has been strongly supported the last two decades by a number of researchers and as such quality of life is now perceived by many as an expression of well-being (see for example [31], [7], [18]). It is increasingly accepted that the assessment of well-being cannot be based entirely on measures of income, wealth and consumption and other less monetary indicators of quality of life need to be considered. As such there is growing interest in exploring policies and practices that enhance well-being rather than economic growth [7] although there is no doubt that income is regarded as a vehicle to achieve an acceptable standard of living.

Quality of life is a multidimensional subject and in this respect its evaluation is a challenge 


\section{Ekonomie}

([21], [31]). Blomquist [5] states that life is good when quality of life is high and claims that this measurement can be based on the things that money can buy such as traditional economic goods (food, shelter, clothing, transportation, entertainment) or less tangible goods (climate, fresh air, clean water, safe neighborhoods, good schools, etc.). The importance of quality of life across cities is further demonstrated by the number of publications that have been developed and rank the quality of life across cities and states based on their observable characteristics [33]. A number of researches rank quality of life based on compensating differentials in labor, housing and consumption markets (see for example [29] and [28]). Roback [28] argued that positive quality-of-life factors in many locations will not only influence levels of wages and rents, but individuals are also willing to trade off higher wages and pay higher rents so that they might live in these communities. Blanchflower and Oswald [4] extended Roback's work and found that individuals are frequently willing to accept higher levels of unemployment in order to live in high-amenity locations.

Blomquist [5] further supports that money income can be used as a metric to measure well-being based on the assumption that more money relaxes the budget constraint and allows a person to make more purchases and achieve a higher level of utility. In this way, the average income in different areas has great value because one can say that households with high incomes are better off because they can buy more. It can be said conclusively that workers accept lower 'real wages' to live in nicer areas. In order to calculate real wages, it is necessary to estimate the cost of living differences across areas and this is a complicated task for the quality of life researchers. The main issues, that arise, concern whether the differences are calculated based on differences in the cost of housing or differences in the prices of non-housing goods. In the latter case, qualitative information is not always available and thus neglected in the calculations. There is criticism however that although incomes do matter to the well-being of individuals that live in a specific area, it is an imperfect measure of utility either because money does not measure the value of the social and natural environment or because it cannot really measure the satisfaction that derives from traditional market goods and their uses [28]. However, as Rappaport [27] observes differences in quality of life will affect individual well-being.

Like beauty, the quality of a natural or nonnatural environment lies in the eyes of the beholder. A particular environment is of low or high quality depending on what the evaluation criteria and its characteristics are. Moreover, the value that economic agents (consumers or producers) assign to it depends upon its scarcity relative to the desire for such environments. Environmental factors are sitespecific; they are located in a given place and thus are part of the wealth of the region in which they are located. However once those environmental factors have been used for economic purposes, the wealth may move to other regions. The overdevelopment of a region whose growth was based on its peculiar environment may, eventually, kill its development. Therefore the importance of regional amenities may vary depending on the stage of the development process. Gunderson et al. [16] in their study on the counties within the states comprising the Four Corners Region of the U.S. (Arizona, Colorado, New Mexico, and Utah) examined the importance of economic and amenity-based variables on net domestic migration flows for the period 1995-2000. The results of the cluster-based technique identified four separate county groups which demonstrate the importance of both economic and amenity-based variables. The impacts of a favorable climate and the presence of numerous natural amenities have been recognized as attractive factors in migration flows.

A study undertaken by Partridge et al. [26] in the U.S. on remoteness and its association with relatively lower economic growth, observed that large cities offer a number of consumer amenities not found elsewhere such as trendy restaurants and advanced healthcare facilities. In the 1990s, U.S. remote areas did not show any significant prosperity as opposed to large metropolitan areas. Naturally the dis-amenities that the large centres present such as environmental pollution and higher crime rates are undisputed, however, there are arguments that quality of life on average most probably increased in large metropolitan areas over the period under examination. The authors used 
a hedonic pricing approach in their research in order to separate household and firm location influences on regional economy. Clearly, consumers show their preference for a specific area by their willingness to accept lower wages. On the other hand, increased productivity advantages are revealed by the increased input costs firms are willing to pay. Remoteness was found to be increasingly associated with lower productivity, contributing to both negative wage and housing cost growth differentials. Yet, remoteness from large metropolitan areas generally became more attractive to households, further contributing to negative wage growth differentials.

In this paper, we present a methodology that let us compare income and housing price differentials by looking at interregional consumers. This classification shows the importance that economic agents put on the characteristics of a region from a microeconomics point of view. Various studies have investigated the existence of consumer income and housing price differentials among regions or cities and concluded that they exist and persist for long periods of time, e.g., [3], [19] and [9]. Within a neo-classical framework in which regions and factors are identical and all economic agents are free to move, these differentials cannot be explained, unless institutional barriers and other impediments to free mobility are introduced in the analysis. In the presence of free mobility, consumer income and housing price differentials can persist because some factors are inherently immobile, e.g. the environmental and climatic characteristics that are unique to a region. It is possible that several regions share the same site-specific characteristics, but it is unlikely that their distribution will be exactly the same.

Economic agents would be willing to pay or accept different level of incomes depending on the value they place on these characteristics. For example, a transportation company may find that its location in a region with good airport(s), port(s), and intra- and intercity transport system saves time and reduces its production costs. This implies that this particular firm can offer relatively higher incomes to its employees and still remain competitive with other transportation companies located in lower-income regions since the characteristics of the transport system of the region is offering it a cost advantage. Since office space and other facilities in the area are limited, the companies attracted by the transport system of the region will increase the demand for both labour and office space. These increases in the prices of labour and office space will continue until in equilibrium they have completely offset the cost advantage of the transport system of the region. Incomes and rents will vary across regions according to the value companies place on the region-specific attributes in each region and their ability to substitute between factors of production.

Similarly, for their own reasons consumers put their own value on a region. Consumers consider the overall environmental quality of a region when they make a decision concerning the place they will live in; where the environmental quality is defined to include all aspects of their environment (natural and nonnatural). They are assumed to consider the distribution of the characteristics of the natural environment and of all regional amenities, including cultural, public services, transport, and other opportunities. In this respect Glaeser et al. [14] identify four general types of urban amenities: variety in private goods and services, including diversity in restaurants and theatres; aesthetics, physical setting, and climate; availability and quality of public goods, including education, health care, and crime protection; and ease of movement for people and goods. The region, for example, with the good transport system that offered a cost advantage to some firms may be attractive to consumers because of reduced travel time to work. Consequently, as more consumers move into the area, the supply of labour increases as well as the demand for housing. Thus rents increase and wages fall until individuals in equilibrium no longer willing to accept moving to a region with a better transport system and a better overall environmental quality as compensation for lower wages and higher rents.

The final income differentials between a geographical area with a good transport system and one without depend upon the relative size of the demand and supply responses to site characteristics. If incomes are observed to be higher in the good transport system area than in the other, then the firm's response dominates the rent determination process. If incomes are relatively lower in the 


\section{Ekonomie}

good transport system area, then the consumer's response dominates the process. In both cases rents will be higher because both households and firms value a good transport system. Rents would be lower than in otherwise comparable geographical areas if the regional transport system was not important to both parties. Consequently, by observing relative consumer incomes and housing prices it is possible to identify whether a region's bundle of environmental and other characteristics has a greater net effect on companies' or consumers' locational decisions.

This paper modifies the Giannias and Liargovas [13] methodology so that the above type of analysis can be applied based on consumers' income and housing prices data availability and identifies Canadian cities according to the extend they are dominated by supply and demand responses to environmental quality which is determined by their net bundle of site specific attributes. It results to classifying Canadian cities (or regions) into four groups based on the relative values of a city's per capita income and housing prices. The cities are then identified as high amenity (low consumer income, high housing prices), low amenity (high consumer income, low housing prices), high productivity (high consumer income, high housing prices), and low productivity (low consumer income, low housing prices). This classification is useful because it provides information about the relative attractiveness to consumers and companies of the total bundle of environmental and other attributes indigenous to each city or region which is determined by the effect of their environmental quality on consumers' utility and producers' output.

\section{The Theoretical Model}

In the following, a model of the effects of interregional differences in amenities and productivity on incomes and housing prices is presented. It will then be demonstrated how this theoretical framework can be used to determine the relative importance of amenity and productivity differences as sources of income and housing price differentials across cities in Canada. In modeling the relationship between interregional differences in amenities and productivity and interregional differences in incomes and rents it is assumed that consumers have identical tastes and skills and are completely mobile, migration is costless, capital is completely mobile, production technologies are identical across companies and exhibit constant returns to scale, and, finally, companies and consumers have chosen locations such that they could not be made better off by relocating.

In our analysis, regions are fully described by a bundle of environmental and other attributes. These specify the environmental quality index of a city or region, EQ, which includes all aspects of natural and non-natural environment of a consumer's life. EQ affects the utility of consumers, $\mathrm{U}($.$) , and the cost of$ production for firms, $\mathrm{C}($.). Individuals in these regions are assumed to consume and produce the numeraire good, $\mathrm{X}$, which is a composite good with a price that is equal to one. Each consumer supplies one unit of labour and receives his income, I, in return. His income is assumed to be a function of the environmental quality of the region, $I=I(E Q)$, and is spent on housing and the numeraire good. The rental price of a house is a function of the vector of housing characteristics, $h$, and the environmental quality of the region, $E Q$, that is, the rental price of a house is specified by the following function: $P=P(h, E Q)$. An equilibrium must be characterized by equal utility for identical consumers and equal unit costs for firms across all regions. A utility maximizing consumer solves the following optimization problem as illustrated in Equation 1:

$\max U(h, X, E Q)$, with respect to $h, X, E Q$

subject to $I(E Q)=P(h, E Q)+X$

where $\mathrm{I}($.$) and \mathrm{P}($.$) are the equilibrium income$ and rental hedonic equations, respectively.

Let $E Q^{*}, h^{*}$, and $X^{*}$ be the solutions to the above utility maximization problem specifying, respectively, the region the consumer will be located, EQ*, the kind of house he will live in, $\mathrm{h}^{*}$, and how much of the numeraire good he will be able to consume, $X^{\star}$. As a result of it, the income of the consumer will be: $I^{*}=I\left(E Q^{*}\right)$, and the rent he will pay for his house: $P^{\star}=P\left(h^{*}\right.$, $\left.E Q^{*}\right)$. Equivalently, the problem can be stated in terms of an indirect utility function $\mathrm{V}($.$) as$ illustrated in Equation 2:

$V\left(I^{\star}, P^{*}, E Q^{*}\right)=\max U\left(h, I^{*}-P^{*}, E Q^{*}\right)$,

with respect to $h$ 
Equilibrium for consumers requires that utility is the same at all regions, that is, $\mathrm{V}(\mathrm{I}, \mathrm{P}, \mathrm{EQ})=\mathrm{v}$, where $\mathrm{v}$ is a constant. This equilibrium condition implies that individuals in regions with better environmental quality pay for it through reductions in real income in the form of higher rent and lower wage income. A cost minimising firm solves the following problem (Equation 3):

$\min I(E Q) L+r K+P(h, E Q)$,

with respect to $L, K, h, E Q$

subject to $X=f(K, L, h, E Q)$

where $\mathrm{K}$ is capital, $\mathrm{L}$ is labour, $\mathrm{I}($.) and $\mathrm{P}($.) are the equilibrium income and rental hedonic equations, respectively, $r$ is the unit price of capital, and $f($.$) is a constant returns to scale$ production in $\mathrm{K}$ and $\mathrm{L}$.

Let $E Q^{*}, h^{*}, K^{*}$ and $L^{*}$ be the solutions to the above cost minimisation problem specifying, respectively, the region the production activity takes place, $\mathrm{EQ}^{*}$, the kind of building or office the company will use, $\mathrm{h}^{\star}$, and how much of capital and labour will employee $\left(K^{*}, L^{*}\right)$. As a result of it, the income that the company will pay to the consumer will be: $I^{*}=$ $\mathrm{I}\left(E Q^{*}\right)$, and the rent he will pay for the building facilities it uses: $P^{\star}=P\left(h^{\star}, E Q^{\star}\right)$. Equivalently, the problem can be stated in terms of a unit cost function $\mathrm{C}($.) as illustrated in Equation 4:

$C\left(I^{\star}, P^{\star}, E Q^{\star}\right)=\min I^{\star} L+r K+P^{*}$,

with respect to $L, K, h$

subject to $X=f\left(K, L, h, E Q^{\star}\right)$

Equilibrium for producers requires that unit cost is the same at all regions, that is, $C(I, P, E Q)$ $=\mathrm{C}$. If the overall environmental quality of a region provides a net productivity advantage to firms, they will pay for it in terms of higher incomes and rents. Wages and rents in each region are finally determined by the interaction of the location decisions of households and firms. The model described above is illustrated in Figure 1. The upward sloping curves in Figure 1, labeled $\mathrm{V}(\mathrm{I}, \mathrm{P} ; \mathrm{EQ})$, shows combinations of $\mathrm{I}$ and $\mathrm{P}$ for which utility is equal to $v$. These are the consumers' iso-environmental quality curves and the $(I, P)$ combinations of each curve correspond to a certain environmental quality values. The slope of these curves is the trade-off that households are willing to make between income and housing prices for any given level of environmental quality (EQ) and the given utility level (v). Along each curve, the environmental quality is fixed and the curves shift up (down) as the environmental quality increases (decreases).

\section{Fig. 1: The consumers' iso-environmental quality curves}

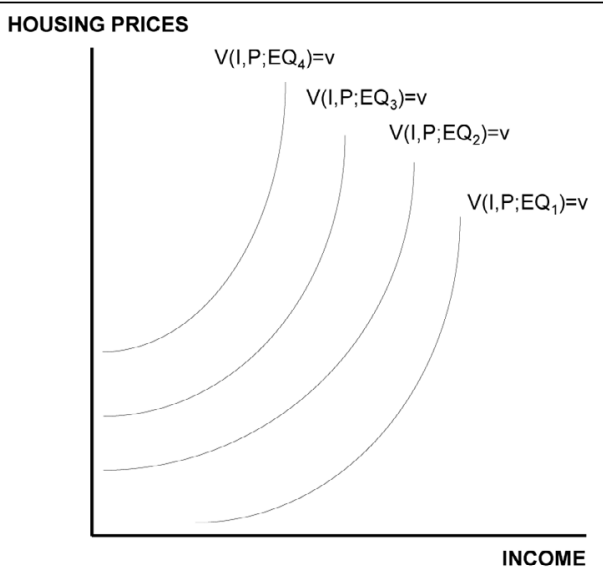

where $E Q 4>E Q 3>E Q 2>E Q 1$, and $v$ is the maximum utility in equilibrium

Source: own

The environmental quality in the region labeled 2 is greater than the one in the region labeled 1; individuals who are paying higher housing prices at every level of income must enjoy in equilibrium a greater environmental quality since their utility must be equal to $\mathrm{v}$, so that there is no incentive for moving to other regions. Combinations of housing prices and income for which the unit costs of firms are equal are provided by the producers' isoenvironmental quality curves in Figure 2 . The value of the environmental characteristics of the region to firms is fixed along each curve, and the curves shift up (down) as the environmental quality of a region increase (decrease) the productivity of firms and the prices of the real estate market. According to Figure 2, the environmental quality in region 2 is greater than that of region 1 , since firms paying higher rental prices at every level of wage income must have higher productivity in equilibrium so that their unit cost is equal to $c$ and there is no incentive for moving to other regions. Each region is characterized by an 


\section{Ekonomie}

environmental quality index and its consumers and producers' iso-environmental quality curves are shown in Figures 1 and 2. The intersection of any two curves for each region then determines the relative income and housing prices in equilibrium.

\section{Fig. 2: The producers'}

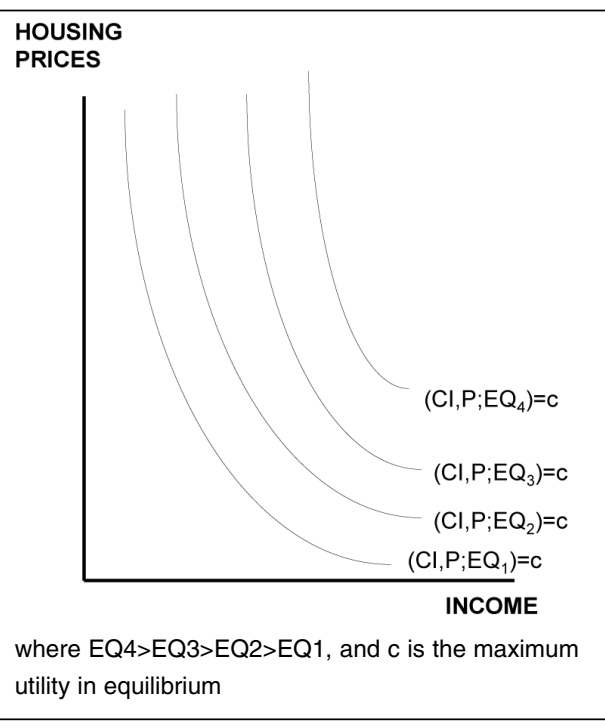

Source: own

In Figure 3, in region 1, where environmental quality equals $E Q_{1}$, the equilibrium income will be $\mathrm{I}_{1}$ and the equilibrium housing prices $P_{1}$. Using region 1 as a reference point, which could be thought as the average region, it is illustrated in the following how interregional differences in environmental quality will be reflected in differences in incomes and rental prices as a result of their effect on consumers' utility and producers' costs. Consider a region 2 that differs from 1 only in that the environmental quality of region 2 is valued more by producers than the environmental quality of region 1 . This implies that, ceteris paribus, rents in region 2 will be relatively higher than rents in region 1 . In Figure 3 , this is illustrated by $C\left(E Q_{2}\right)$ lying above $C\left(E Q_{1}\right)$. Assuming there is no difference in environmental quality between the two regions from the consumers' point of view, it is demonstrated that equilibrium requires that incomes and housing prices in region 2 be higher relative to region 1 . The higher housing prices and incomes reflect the amount firms are willing to pay to locate in region 2 rather than 1 and, therefore, the productivity value of $E_{2}$ relative to the average region. Moreover, since from a consumer's point of view there is no difference in environmental quality between the two regions, the effects of higher housing prices and incomes on their utility must offset each other so that their maximum utility remains in equilibrium equal to $\mathrm{v}$.

\section{Fig. 3: \\ Relative income and housing prices in equilibrium $\left(E Q_{2}>E Q_{1}\right)$}

\section{HOUSING PRICES}

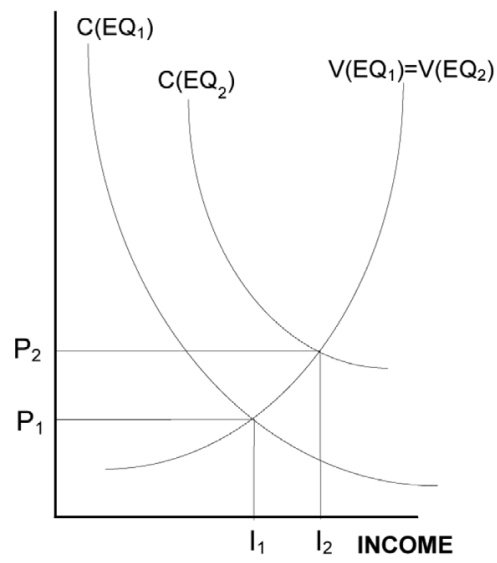

Source: own

Consider another region, region 3 that differs from 1 only in that the environmental quality $E Q_{3}$ is having a greater effect on consumers' utility. This implies that, ceteris paribus, housing prices in region 3 will be relatively higher than in region 1. This relationship is illustrated in Figure 4, where region 3 is represented by $\mathrm{V}\left(\mathrm{EQ}_{3}\right)$ which is to the left of $V\left(E Q_{1}\right)$. If no amenity differences exist from a producer's point of view, then it is clear that the equilibrium requires that incomes in region 3 are lower relative to region 1 . The higher housing prices and lower incomes reflect the amount consumers are willing to pay to locate in region 3 rather than 1 , and therefore, the value of the effect of $\mathrm{EQ}_{3}$ on consumers' utility relative to the average region. Moreover, since from the producer's point of view there is no difference in environmental quality between 
regions 1 and 3 , the effects of higher rents and lower incomes on producers must offset each other so that the unit cost that a producer faces in equilibrium remains equal to $\mathrm{c}$.

Fig. 4: Relative income and housing prices in equilibrium $\left(E Q_{3}>E Q_{1}\right)$

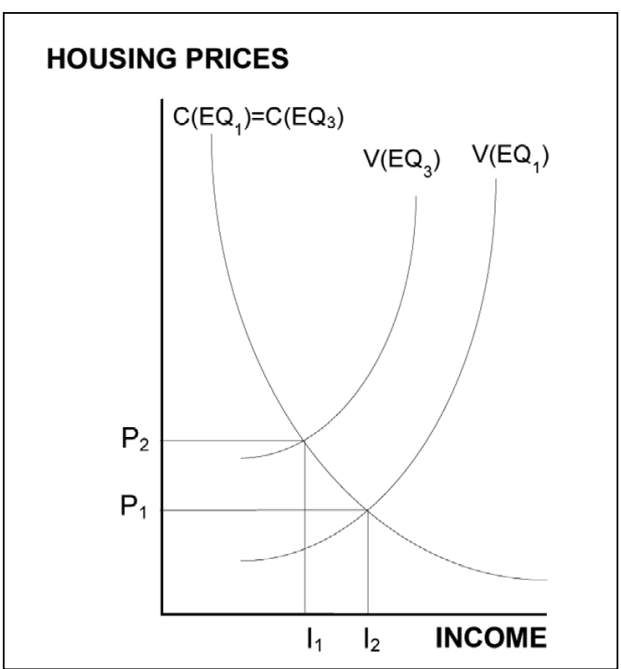

Source: own

Given the cases of Figures 3 and 4 and assuming that environmental quality has some effect on both consumers and producers, the case of Figure 5 is examined, where: (i) when environmental quality is valued relatively more by producers, ceteris paribus, $\mathrm{C}\left(\mathrm{EQ}_{2}\right)$ has been moved up relatively more than $\mathrm{V}\left(E Q_{2}\right)$, and (ii) when environmental quality is valued relatively more by consumers, ceteris paribus, $\mathrm{V}\left(\mathrm{EQ}_{3}\right)$ has moved up relatively more than $C\left(E Q_{3}\right)$. Within this simple framework in which regions differ only in their environmental quality, it can be determined whether housing prices and income differences reflect interregional differences in amenities or productivity by examining the patterns of housing prices and incomes across regions. If housing prices and income differences primarily reflect amenity differences across regions, a negative relationship between housing prices and incomes would be observed. If they reflect productivity differences, the relationship would be positive.
Relative income and housing prices in equilibrium $\left(E Q_{3}>E Q_{2}>E Q_{1}\right)$

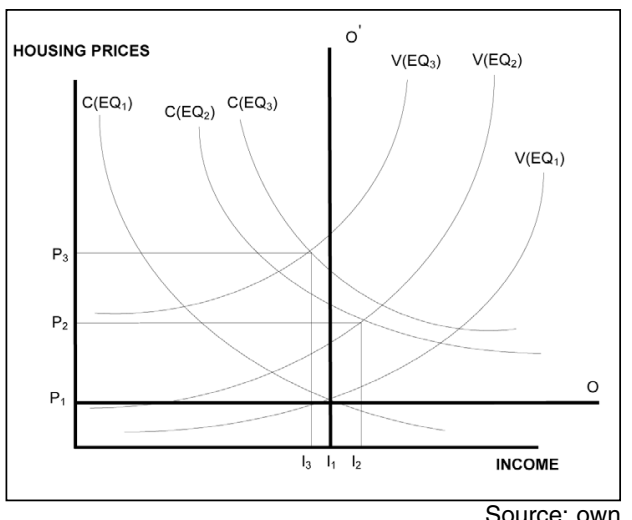

Within the same framework, individual regions can also be classified on the basis of whether their incomes and housing prices differ from the average because of above average amenities, below average amenities, above average productivity, or below average productivity. These classifications are summarized in Table 1 and Figure 6. Housing prices are higher than the average in the high amenity and high productivity regions and lower than the average in the low amenity and low productivity ones. On the other hand, incomes are relatively higher in the high productivity and low amenity regions.

\section{Fig. 6: Region classification using incomes and housing prices}

\section{HOUSING PRICES}

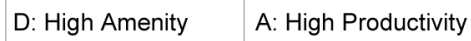

C: Low Productivity B: Low Amenity

INCOME 


\section{Ekonomie}

Tab. 1: Region classification using incomes and housing prices

\begin{tabular}{l|c|c|c} 
Classification & Income & Housing price & $\begin{array}{c}\text { Shift of ISO-Environmental } \\
\text { quality curve }\end{array}$ \\
\hline High productivity & High & High & $\mathrm{C}\left(\mathrm{EQ}_{1}\right)$ curve up \\
\hline Low productivity & Low & Low & $\mathrm{C}\left(\mathrm{EQ}_{1}\right)$ curve down \\
\hline High amenity & Low & High & $\mathrm{V}\left(\mathrm{EQ}_{1}\right)$ curve up \\
\hline Low amenity & High & Low & $\mathrm{C}\left(E Q_{1}\right)$ curve down \\
\hline
\end{tabular}

Source: own

Each region is characterized by an environmental quality index, EQ, whose effect on household utility and production costs differs from region to region. The problem of classifying regions by the relative magnitude of these two effects becomes one of identifying the housing price and income differences in equilibrium relative to the shifts in each iso-environmental quality curve. This can be done by identifying the combinations of $P$ and $I$ in equilibrium that are associated with equal shifts of both curves and determining how incomes and environmental quality change relative to these shifts. The $(P, I)$ combinations associated with equal shifts of both curves would coincide with the $\mathrm{P}_{1} \mathrm{O}$ and $\mathrm{I}_{1} \mathrm{O}^{\prime}$ lines in Figure 5, 6, and 7, where $\mathrm{P}_{1}$ is the mean housing price and $\mathrm{I} 1$ is the mean income. For any region with above average incomes and housing prices, the shift of the $C(R)$ curve must be greater than the shift of the $V(E Q)$ curve. The less the direct effect of environmental quality on utility, the greater the increase in consumer income needed to offset the increase in rents and, consequently, the smaller the shift of the $V(R)$ curve needed to keep the maximum utility level unchanged and equal to $v$ in equilibrium. Therefore, any region with housing prices and income combinations in quadrant $A$ in Figure 6 is classified as "high productivity" region, because the primary reason that this region incomes, environmental quality, and housing prices differ from those of the average region is the above-average productivity effects of environmental quality. This above-average productivity effect is reflected in the ability of producers in these regions to pay above average incomes and rents for having at their disposal a greater than the average environmental quality.

Similarly regions with below average incomes and housing prices (quadrant $C$ in Figure 6 ) are classified as "low productivity" regions, since firms in these regions are compensated for the below average environmental quality effect on productivity with below-average rental prices and income. Above average amenity effects of a region are associated with increases in housing prices and decreases in incomes reflecting consumers' willingness to pay relatively more for the effects of the regional characteristics embodied in the region's environmental quality. Quadrant $D$ then identifies regions where the environmental quality is greater then the average and the dominant factor determining relative incomes and housing prices is the relatively high effect of environmental quality on consumers' utility. For regions in quadrant B, the dominant factor is their below-average amenity value. These labels may be misleading in that what it is being referred to as "high productivity" regions which are not necessarily more or less attractive to households than the "high amenity" regions. A region like the one represented by point $A$ in Figure 7 is relatively more attractive to households and firms than region 1.

This relationship can been seen by the position of the $C\left(E Q_{A}\right)$ and $V\left(E Q_{A}\right)$ curves relative to the average region. The effect that dominates, however, is the productivity effect, since the shift of the $C(E Q)$ curve is relatively greater than the shift of the $V(E Q)$ curve. If the shift of the $C(E Q)$ curve was equal to that of $V\left(E Q_{A}\right)$, that is, if it had moved to the position $C\left(E Q_{A}\right.$ ') instead of $C\left(E Q_{A}\right)$, the equilibrium would be at point $A^{\prime}$ and the region would not be able to be characterised neither as high or low amenity nor as high or low productivity. Another region like the one represented by point $B$ may be less attractive to both firms and households than region $A$ (again reflected in the relative positions of the amenity and 


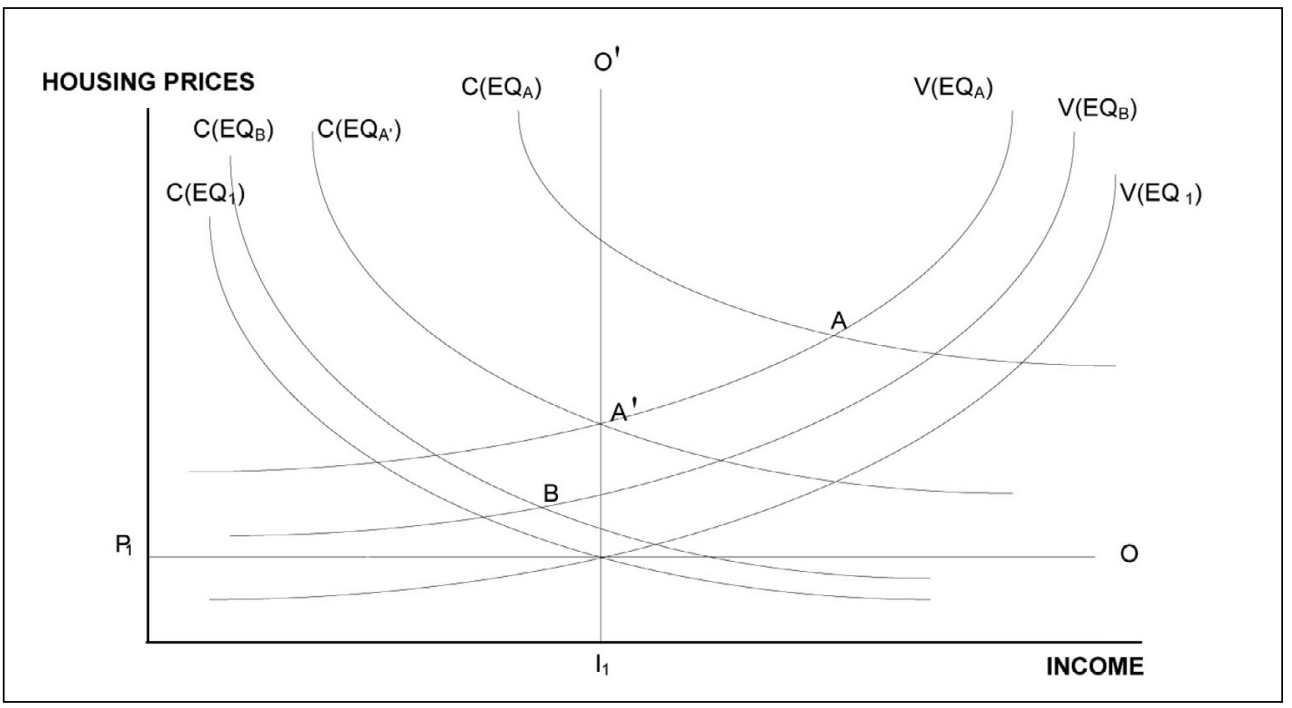

Source: own

productivity curves). However, the dominant trait of region $B$ is its amenity, which is above average.

\section{An Amenity-Productivity Classification}

Assume that the rental prices are determined by a vector of variables $y$. For example, some of these variables may be: structural condition, age, neighborhood, crime rate, number of floors, number of rooms, central air conditioning, humidity, precipitation, sunshine etc; for an indicative list of such variables see, for example, Bloomquist et al. [6], and Harrison and Rubinfeld [17]. Subsequently assume that the vector $y$ consists of two vectors $x$ and $z$, that is, $y=x+z$. We may think of 1) $x$ as a vector of variables that affect rental prices and which are easy to quantify; for example, number of rooms, number of bathrooms, age of building, and 2) $z$ as a vector of variables that affect rental prices, too, and which describe more qualitative factors such as environmental issues and quality of life which are non-tangible and thus more difficult to quantify. The housing price index (HPI) or else the rental price of a house can be expressed as a function of these variables. To be more specific as illustrated in Equation 5:
$H P I=f\left(x_{1}, x_{2}, x_{3}, x_{4}, \ldots, x_{n}, z_{1}, z_{2}, z_{3}\right.$,

$\left.z_{4}, \ldots z_{m}\right)$

where

$x=\left(x_{1}, x_{2}, x_{3}, x_{4}, \ldots, x_{n}\right)$ and $z=\left(z_{1}, z_{2}, z_{3}\right.$, $\left.z_{4}, \ldots z_{m}\right)$

A classification of the type of Figure 6 is possible to be obtained either for the set of variables $(\mathrm{x}, \mathrm{z})$, or $\mathrm{x}$, or $\mathrm{z}$. This is explained further next. Using market data on housing prices, $\mathrm{HPI}$, and consumer income, I, we can make the classification illustrated in Figure 6 . This classification incorporates the effect of the whole set of variables $(x, z)$ that determine rental prices HPI.

Let $x$ be, too, the set of variables explicitly included in an estimated hedonic (rental) price equation; and suppose that the following equation gives the estimated housing prices, HPI, where

$$
\overline{\mathrm{HPI}}=\alpha+\beta_{1} x_{1}+\beta_{2} x_{2}+\ldots+\beta_{n} x_{n}
$$

$\alpha, \beta_{1}, \beta_{2}, \ldots \beta_{\mathrm{n}}$ are ordinary least squares that derive through empirical studies. Then we can make a classification of the type of Figure 6 using the $(\overline{\mathrm{HPI}}, \mathrm{I})$ figures. This incorporates the effect of the $x$ set of variables. Finally, a classification based on the (HPI- $\overline{\mathrm{HPI}}, \mathrm{I})$ is 


\section{Ekonomie}

determined by the effect of the $z$ set of variables. In order to proceed to a classification analysis (of the type outlined above) for a subset of variables $x$ or $z$, hedonic rental prices estimates are needed. This is illustrated below using the hedonic price estimates of Giannias [12] for Canadian cities.

\section{An Amenity-Productivity Classification of Canadian Cities}

As an illustration, the results of the above analysis are used to investigate which of the Canadian cities: Calgary, Vancouver, Edmonton, Winnipeg, Toronto, Ottawa-Hull, Halifax, Montreal, and Quebec were relatively more or less attractive to firms and households in early 90 's. The quality of life of these cities was analyzed within a hedonic framework (for the same time period) as in Giannias [12]; the results of this article are used below to illustrate how the hedonic approach can be used in a regional analysis based on the classification system presented herein (the objective of the article is to illustrate the methodology presented in this article. This and the fact that rental housing prices are not in general available justify why the authors have decided to use the empirical results of Giannias [12]).

To see this, we must first put the relevant housing prices and income figures on Figure 6. For this purpose, we used the 1982-1983 data given in Table 2, where HPI is a housing price index and $\mathrm{Ml}$ is the mean per capita income of a city.

\section{Tab. 2: 1982-1983 data for the housing price index and mean per capita income for Canadian cities}

\begin{tabular}{l|c|c}
\hline CITY-REGION & HPI & MI \\
\hline CALGARY & 182.00 & $14,970.50$ \\
\hline VANCOUVER & 163.20 & $14,918.00$ \\
\hline EDMONTON & 189.70 & $14,546.00$ \\
\hline WINNIPEG & 165.20 & $12,429.00$ \\
\hline TORONTO & 151.10 & $14,219.50$ \\
\hline OTTAWA-HULL & 152.70 & $14,481.50$ \\
\hline HALIFAX & 142.50 & $12,364.00$ \\
\hline MONTREAL & 150.20 & $13,788.00$ \\
\hline QUEBEC & 161.40 & $14,046.00$ \\
\hline
\end{tabular}

Source: [12]

The pertinent mapping, for the above mentioned cities and time period, is given in Figure 8, where the HPI and MI values of each city have been employed.

Figure 8 is based on statistical data and gives a positioning of Canadian cities on a rental prices - mean income mapping, which incorporates the effects of the whole set of variables, $y$. The gray zones represent a $\pm 1 \%$ on both the mean housing price index and mean income of all cities. When the data position a city within this $\pm 1 \%$ (grey colored) intervals, the conclusions for this city are not clear and need further investigation. The following graph (Figure 9) is based on the data of Table 3, where the estimated hedonic rental prices ( $\overline{\mathrm{HPI}})$ for each city, are obtained from Giannias (1998). The classification of Figure 9 incorporates the effects of variables included in the vector $x(=y-z$ from the above $)$ and explicitly included in the hedonic rental estimated equation. 


\section{Fig. 8: Amenity-Productivity classification based on the effects of all variables $(x, z)$}

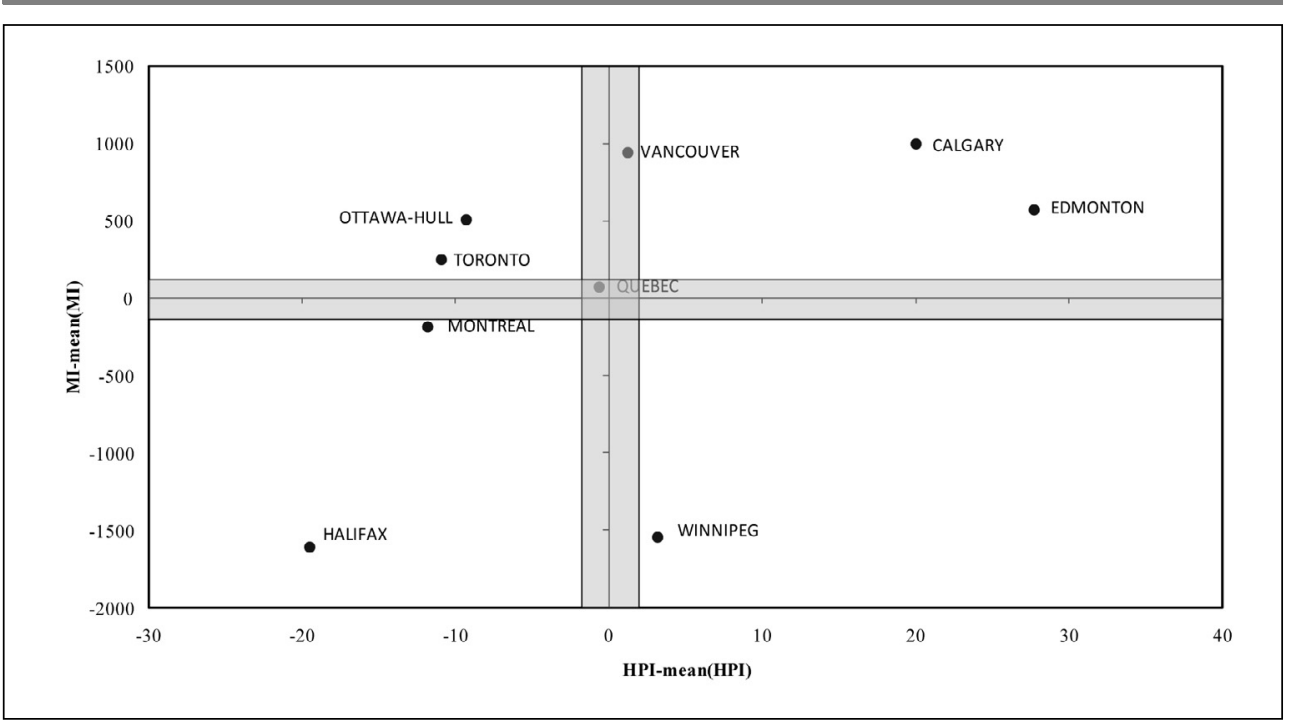

Source: own

Tab. 3: Estimated housing price index and mean per capita income of a Canadian city
\begin{tabular}{l|c|c} 
City-Region & $\overline{\text { HPI }}$ & MI \\
\hline Calgary & 367.92 & $14,970.50$ \\
\hline Vancouver & 326.68 & $14,918.00$ \\
\hline Edmonton & 254.13 & $14,546.00$ \\
\hline Winnipeg & 223.78 & $12,429.00$ \\
\hline Toronto & 162.59 & $14,219.50$ \\
\hline Ottawa-Hull & 120.01 & $14,481.50$ \\
\hline Halifax & 93.67 & $12,364.00$ \\
\hline Montreal & 89.76 & $13,788.00$ \\
\hline Quebec & 5.53 & $14,046.00$ \\
\hline
\end{tabular}

Source: own

The last graph presented herein represents the classification of the specific Canadian cities which is based on rental price variations due to variation in the values of vector $z$ across cities, thus producing ultimately a more qualitative evaluation of the cities in question (see Table 4 and Figure 10). These variations in rental prices due to variations in the values of vector $\mathrm{z}$ are captured by the $\mathrm{HPI}-\overline{\mathrm{HPI}}$ value for each city. In essence Figure 10 illustrates the potential to incorporate in the analysis and the classification of the type we study in this article of qualitative attributes (i.e., variables in the $z$ vector) such as the environment or the quality of life. These are attributes which are difficult to be quantified and evaluated. When, therefore, a number of tangible factors (such as the number of rooms or bathrooms) can be measured and illustrated graphically, then the qualitative parameters such as the environment or quality of life can be illustrated graphically and evaluated accordingly. 


\section{Ekonomie}

\section{Fig. 9: Amenity-Productivity classification based on a subset of variables (x) - the case of quantitative variables}

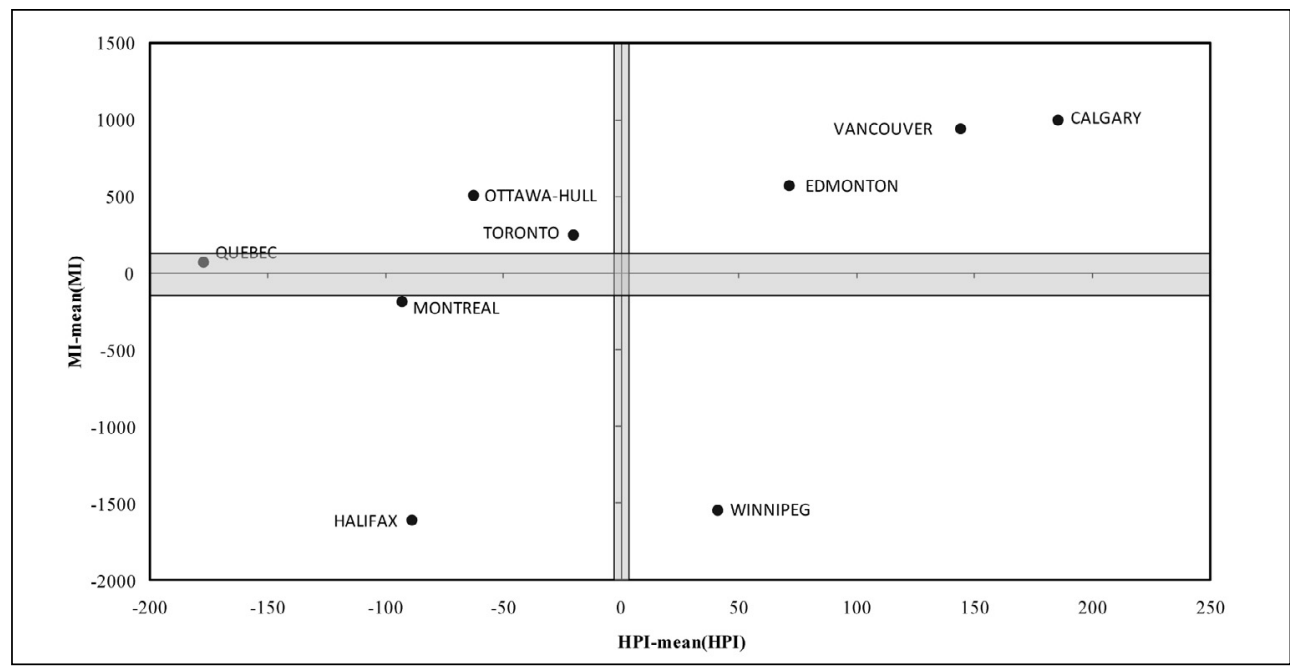

Source: own

\section{Tab. 4:}

Housing price index, estimated housing price index $\mathbf{n}$ and and mean per capita income of a Canadian city

\begin{tabular}{l|c|c|c|c} 
City-Region & HPI & $\overline{\text { HPI }}$ & HPI- $\overline{\text { HPI }}$ & MI \\
\hline Calgary & 182.00 & 367.92 & -185.92 & $14,970.50$ \\
\hline Vancouver & 163.20 & 326.68 & -163.48 & $14,918.00$ \\
\hline Edmonton & 189.70 & 254.13 & -64.43 & $14,546.00$ \\
\hline Winnipeg & 165.20 & 223.78 & -58.58 & $12,429.00$ \\
\hline Toronto & 151.10 & 162.59 & -11.49 & $14,219.50$ \\
\hline Ottawa-Hull & 152.70 & 120.01 & 32.69 & $14,481.50$ \\
\hline Halifax & 142.50 & 93.67 & 48.83 & $12,364.00$ \\
\hline Montreal & 150.20 & 89.76 & 60.44 & $13,788.00$ \\
\hline Quebec & 161.40 & 5.53 & 155.87 & $14,046.00$ \\
\hline
\end{tabular}

Source: own

Table 5 summarizes the results of the three different graphs based on the classification provided in Figure 6, i.e. high and low productivity, and high and low amenity. The results for the Canadian cities under examination are clear with the exception of Quebec for all three different criteria that have been examined and Vancouver for the criterion of HPI-MI. These exceptions are highlighted with gray in Table 5 and illustrate the gray zones demonstrated in Figures 8, 9 and 10. In the cases of gray zones, it is impossible to form accurate conclusions as to the amenityproductivity classification of the city. What can be concluded however, is which are the classification(s) of Figure 6 that cannot be assigned to the city under examination. As such, in the case of Quebec, what can be concluded is that for the first criterion (HPI, MI), the city is neither Low Amenity nor Low Productivity. For the second criterion $(\overline{\mathrm{HPI}}, \mathrm{MI})$, the city is neither High Productivity nor Low Amenity and for the last criterion ((HPI- $\overline{\mathrm{HPI}}), \mathrm{MI})$, it is neither High Amenity nor Low Productivity. 
Fig. 10: Amenity-Productivity classification based on a subset of variables (z) - the case qualitative variables

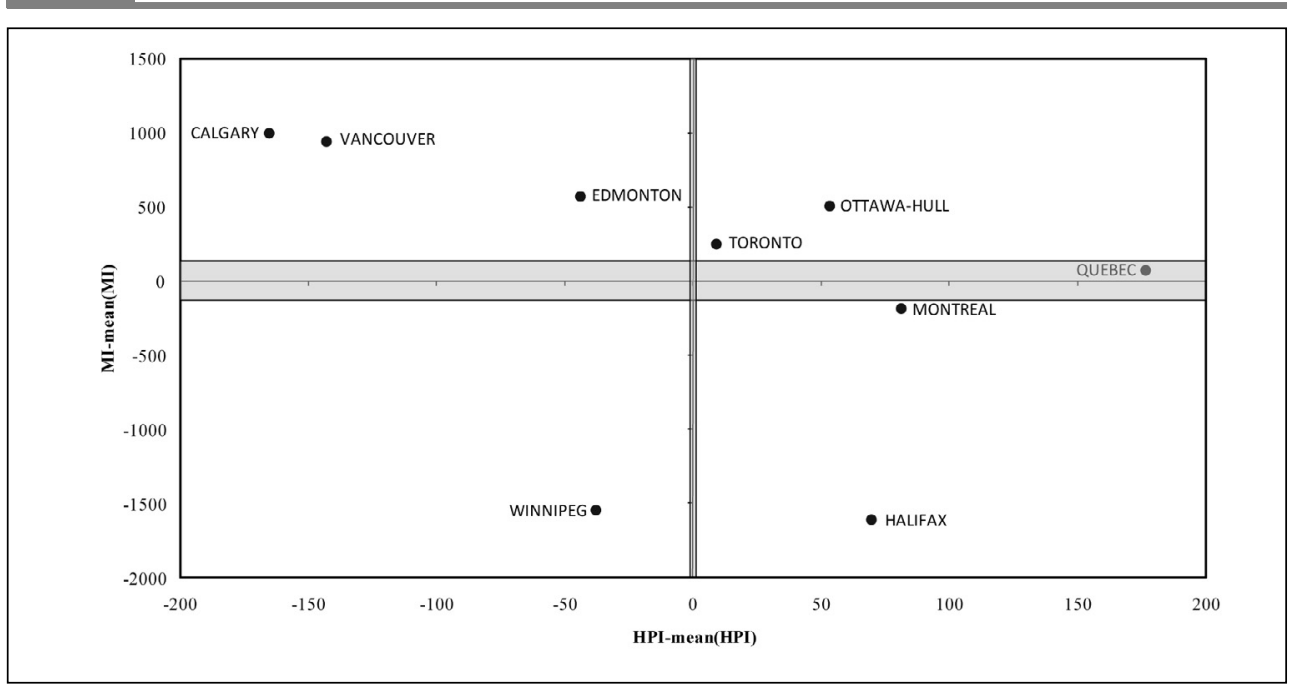

Source: own

Tab. 5: Summary of results from graphs 8,9 and 10

\begin{tabular}{l|c|c|c} 
City-Region & HPI-MI & $\overline{\text { HPI-MI }}$ & (HPI- $\overline{\text { HPI)-MI }}$ \\
\hline Calgary & High Productivity & High Productivity & High Amenity \\
\hline Vancouver & High Productivity & High Productivity & High Amenity \\
\hline Edmonton & High Productivity & High Productivity & High Amenity \\
\hline Winnipeg & Low Amenity & Low Amenity & Low Productivity \\
\hline Toronto & High Amenity & High Amenity & High Productivity \\
\hline Ottawa-Hull & High Amenity & High Amenity & High Productivity \\
\hline Halifax & Low Productivity & Low Productivity & Low Amenity \\
\hline Montreal & Low Productivity & Low Productivity & Low Amenity \\
\hline Quebec & High Amenity & High Amenity & High Productivity \\
\hline
\end{tabular}

Source: own

Lastly for the case of Vancouver, for the first criterion, for which Vancouver falls in the gray zone, the conclusion that can be derived is that it is neither Low Amenity nor Low Productivity.

\section{Conclusions}

An analysis of consumer's and firm's behavior, under the assumption that environmental quality and housing quality are two differentiated goods, shows that it is possible to obtain a classification of the effects of environmental quality on consumers' utility and producers' costs based on housing prices and income differentials. Assuming that the rental prices can be expressed as a function of a large number of variables which can be broadly divided to quantitative (i.e. number of rooms) and qualitative (i.e. quality of life), an amenity-productivity classification can be produced either for the whole set of variables or for each set. Three different criteria have been developed employing a) housing prices (all variables) and consumer income (HPI-l), b) estimated hedonic rental prices (quantitative variables) and consumer income $(\overline{\mathrm{HPI}}-\mathrm{I})$ and c) the difference of housing prices 


\section{Ekonomie}

and estimated hedonic rental prices (qualitative variables) and consumer income (HPI- $\overline{\mathrm{HPI}}, \mathrm{I})$.

Although the first two criteria provide useful insights with respect to the amenity-productivity classification of cities, the conclusions that derive from the last criterion (HPI- $\overline{\mathrm{HPI}}, \mathrm{I})$ produce a qualitative evaluation of cities. Considering the non-quantifiable nature of many factors, it is clear that this criterion offers a tool for measuring qualitative attributes and therefore a basis for evaluation and comparison. The methodology presented was in turn applied to a number of Canadian cities for which the amenity-productivity classification was produced for all three criteria. Cities were then classified as Low/High Amenity and Low/High Productivity providing useful information as to their relative attractiveness to firms and households.

\section{References}

[1] BAUMOL, W.J., OATES, W.E. The theory of environmental policy: Externalities, public outlays and the quality of life. Englewood Cliffs (NJ): Prentice-Hall, 1975. ISBN 978-0139136733.

[2] BECKERMAN, W. Two cheers for the affluent society, A spirited defence of economic growth. New York: St. Martin's Press, 1975. ISBN 978-0312826000.

[3] BELLANTE, D. The North-South Differential and the Migration of Heterogeneous Labour. American Economic Review. 1979, Vol. 69, No. 1, pp. 166-175. ISSN 0002-8282.

[4] BLANCHFLOWER, D., OSWALD, A. The Wage Curve. Cambridge (MA): MIT Press, 1994. ISBN 978-0-262-02375-7.

[5] BLOMQUIST, G.C. Quality of Life. In ARNOTT, R, McMILLEN, D. (Eds.). A Companion to Urban Economics. Malden (MA): Blackwell Publishing, 2006. ISBN 978-1405179683.

[6] BLOMQUIST, G., BERGER, M., HOHEN, J. New Estimates of Quality of Life in Urban Areas. American Economic Review. 1988, Vol. 78, pp. 89-107. ISSN 0002-8282.

[7] CAGLIERO, R., CRISTIANO, S., PIERANGELI, F., TARANGIOLI, S. Evaluating the Improvement of Quality of Life in Rural Areas. Paper prepared for the 122nd EAAE Seminar "Evidencebased agricultural and rural policy making: methodological and empirical challenges of policy evaluation", 2011, Ancona, February 17-18.

[8] EASTERLIN, R.A. Does money buy happiness? The Public Interest. 1973, Vol. 30, pp. 3-10. ISSN 0033-3557.
[9] EBERTS, R.W., STONE, J.A. Metropolitan Wage Differentials: can Cleveland Still Compete? Economic Review - Federal Reserve Bank of Cleveland. 1986, Iss. Q II, pp. 2-8. ISSN 0013-0281. [10] FORRESTER, J.W. World dynamics. Cambridge (MA): Wright - Allen, 1971. ISBN 0262060663.

[11] GALBRAITH, J.K. The affluent society. Boston: Houghton Mifflin, 1958. ISBN 978-0395925003. [12] GIANNIAS, D.A. A Quality of Life Based Ranking of Canadian Cities. Urban Studies. 1998, Vol. 35, No. 12, pp. 2241-2251. ISSN 0042-0980. [13] GIANNIAS, D.A. and LIARGOVAS, P.G. Firm and household mobility in the presence of variations in regional characteristics. The Annals of Regional Science. 2002, Vol. 36, No. 4, pp. 299-313. ISSN 0570-1864.

[14] GLAESER, E.L., ROSENTHAL S.S. and STRANGE W.C. Urban economics and entrepreneurship. Journal of Urban Economics. 2010, Vol. 67, Iss. 1, pp. 1-14. ISSN 0094-1190.

[15] GRIFFIN, J. An econometric evaluation of sulphur taxes. Journal of Political Economy. 1974, Vol. 82, No. 4, pp. 669-688. ISSN 0022-3808.

[16] GUNDERSON, R.J., PINTO J.V., WILLIAMS, R.H. Economic or Amenity Driven Migration? A Cluster-Based Analysis of County Migration in the Four Corners States. The Journal of Regional Analysis \& Policy. 2008, Vol. 38, No. 3, pp. 243-254. ISSN 10904999.

[17] HARRISON, D., RUBINFELD, D.L. Hedonic housing prices and the demand for clean air. Journal of Environmental Economics and Management. 1978, Vol. 5, Iss. 1, pp. 81-102. ISSN 0095-0696.

[18] JOHANSSON, S. Conceptualizing and measuring quality of life for national policy. Social Indicators Research. 2002, Vol. 58, No. 1/3, pp. 13-32. ISSN 0303-8300.

[19] JOHNSON, G.E. Intermetropolitan Wage Differentials in the United States. In TRIPLETT J.E. (Ed.). The Measurement of Labour Cost. Chicago: University of Chicago Press, 1983. ISBN 0-226-81256-1.

[20] KING, M.A. Economic Growth and Social Development - A statistical investigation. Review of Income and Wealth Series. 1974, Vol. 20, No. 3 , pp. 251-272. ISSN 0034-6586.

[21] LAYARD, R. Rethinking public economics: The implications of rivalry and habit. In BRUNI, L., PORTA, P.L. (Eds.). Economics and Happiness: Reality and Paradoxes. Oxford: Oxford University Press, 2005. ISBN 0-19-928628-0. 
[22] MEADOWS, D.H., MEADOWS, D.L., RANDERS, J., BEHRENS, W.W. The limits to growth. A report for the Club of Rome's project on the predicament of mankind. New York: Universe Books, 1972. ISBN 0876631650.

[23] MISHAN, E.J. The cost of economic growth. London: Staple Press, 1967. ISBN 978-0275947033. [24] MULLIGAN, G.F., CARRUTHERS, J.I., and CAHILL, M. Urban Quality of Life and Public Policy: A Review. In CAPELLO, R., NIJKAMP, P. (Eds.). Urban Dynamics and Growth. Amsterdam: Elsevier, 2004. pp. 729-802. ISBN 0444514813. [25] NORDHAUS, W.D., TOBIN, J. Is Growth Obsolete? In Economic Growth. General Series No. 96. New York: National Bureau of Economic Research, 1972. pp.1-80. ISBN 0-87014-254-2.

[26] PARTRIDGE, M.D., RICKMAN, D., ALI, K., OLFERT, R.M. Lost in Space: Population Dynamics in the American Hinterlands and Small Cities. Journal of Economic Geography. 2008, Vol. 8, No. 6, pp. 727-757. ISSN 1468-2702.

[27] RAPPAPORT, J. The increasing importance of quality of life. Journal of Economic Geography. 2009, Vol. 9, No. 6, pp. 779-804. ISSN 1468-2702. [28] ROBACK, J. Wages, rents, and the quality of life. Journal of Political Economy. 1982, Vol. 90, No. 6, pp. 1257-1278. ISSN 0022-3808.

[29] ROSEN, S. Wage-based indexes of urban quality of life. In MIESKOWSKI, P., STRASZHEIM,
M. (Eds.). Current Issues in Urban Economics. Baltimore: Johns Hopkins University Press, 1979. pp. 74-104. ISBN 978-0801821844.

[30] SMITH, D.M. Human Geography: A Welfare Approach. London: Edward Arnold, 1977. ISBN 0713159251.

[31] STIGLITZ, J.E., SEN, A., FITOUSSI, B. Report by the Commission on the Measurement of Economic Performance and Social Progress [online]. 2009 [cit. 2012-07-27]. 292 p. (PDF). Available from: http://www.stiglitz-sen-fitoussi.fr/ documents/rapport_anglais.pdf.

[32] WALTERS, A.A. Noise and prices. London: Oxford University Press, 1975. ISBN 9780198281979. [33] WINTERS, J.V. Differences in Quality of Life Estimates Using Rents and Home Values. Munich: Personal RePEc Archive, April 2010. ID CODE: 24270.

Dimitrios Giannias, Ph.D., M.Sc., M.A., B.A. Hellenic Open University School of Social Sciences dgiannias@gmail.com

Eleni Sfakianaki, Ph.D., M.Sc., Dip. Eng. Hellenic Open University School of Social Sciences esfakianaki@eap.gr 


\section{Ekonomie}

\section{Abstract}

\section{CLASSIFICATIONS OF ENVIRONMENTAL QUALITY EFFECTS: THE CASE OF CANADIAN CITIES}

\section{Dimitrios Giannias, Eleni Sfakianaki}

Amenities are goods and services that make certain locations attractive for living and working. Quality of life on the other hand can be perceived as an expression of well-being and its importance is demonstrated by a number of publications that have been developed and rank quality of life across cities and states based on their observable characteristics. Amenities' assessments are employed in order to produce an index to rate quality of life. It is increasingly accepted that wellbeing cannot be entirely based on measures of income, wealth and consumption. Other indicators more qualitative (i.e. environment) should be considered. In the broader context, quality of life measures traditional economic goods such as food and accomodation but also more qualitative factors such as environmental and social (i.e. fresh air, low criminality). Environmental factors located in a given place can be considered as part of the wealth of the region in which they are located. A classification of the effects of environmental quality on consumers' utility and producers' costs that is based on housing prices and income differentials is useful because it provides information about the relative attractiveness to them of the total bundle of environmental and other attributes indigenous to each region. A theory is presented for this kind of analysis and classifications producing a qualitative evaluation of cities. The methodology used a number of Canadidan cities as a case study. An amenity-productivity classification was produced and cities were eventually classified as Low/High Amenity and Low/High Productivity providing useful information as to their relative attractiveness to firms and households.

Key Words: Environmental quality, housing prices, consumer income.

JEL Classification: Q000, R00, D11, D21, H40, 131.

DOI: 10.15240/tul/001/2014-2-004 